\title{
A Study of the Photocatalytic Degradation of Acetaldehyde
}

\author{
Suresh C. Ameta ${ }^{1}$ and Chetna Gomber ${ }^{2}$
}

${ }^{1}$ Photochemistry and Solar Energy Laboratory, Department of Chemistry, University College of Science, M. L.

Sukhadia University, UDAIPUR - 313002 (Raj.) INDIA

${ }^{2}$ correspondence: Department of Chemistry, JIET School of Engineering And Technology For Girls, JIET

Universe, N.H-65, Pali Road, Mogra, Jodhpur-Rajasthan, INDIA

$$
\text { Email:chirag11gomber@gmail.com }
$$

\section{ABSTRACT}

Photocatalytic degradation of acetaldehyde over cadmium sulfide, a semiconductor was investigated. The effect of various parameters, such as $\mathrm{pH}$, concentration of acetaldehyde, amount of semiconductor, effect of light intensity were observed. A tentative mechanism has been proposed for the photocatalytic degradation of acetaldehyde using cadmium sulphide semiconductor.

\section{Keywords}

photocatalytic degradation, acetaldehyde, cadmium sulphide, semiconductor

\section{SUBJECT CLASSIFICATION}

Chemistry: PHOTOCHEMISTRY

\section{Council for Innovative Research}

Peer Review Research Publishing System

\section{Journal: Journal of Advances in Chemistry}

Vol. 5, No. 1

editor@cirworld.com

www.cirworld.com, member.cirworld.com 


\section{INTRODUCTION}

The large amount of solar energy falling on earth can be best utilized to degrade larger molecules into smaller fragments. This serves to protect the environment as it helps to mineralize toxic compounds to less toxic or almost harmless species. These reactions can be supported by using a photocatalyst (semiconductor) in the presence of light, diverting the reaction to photocatalytic route.

The field of photocatalysis has been excellently reviewed by Tanaka ${ }^{1}$, Steinbach ${ }^{2}$, Pelizetti et al. ${ }^{3}$, and Ameta et al. ${ }^{4}$ Matsuoka et al. ${ }^{5}$ observed the visible light driven and poly (pyridine-2,5- diyl)-catalysed hydrogen photoevolution and photoreduction of carbonyl compounds. Ikeda et al. ${ }^{6}$ observed a comparative study on the photocatalytic decomposition of acetaldehyde and ethanol in water containing dissolved oxygen using a microelectrode technique. Photocatalytic dehydrogenation of hexanal and reductive carbonylation of pentane by $\mathrm{Rh}$ (I) complexes has been reported by Khannanov et al. ${ }^{7}$ Sano et al. ${ }^{8}$ investigated the photocatalytic degradation of gaseous acetaldehyde on $\mathrm{TiO}_{2}$ with photodeposited metals and metal oxides. Photocatalytic degradation of acetaldehyde on mesosporous $\mathrm{TiO}_{2}$ has been reported by $\mathrm{Fan}$ et al. Carrera et al. ${ }^{10}$ observed photocatalytic degradation of acetaldehyde by sol-gel $\mathrm{TiO}_{2}$ nanoparticles.

Acetaldehyde exhibits narcotic action and large doses may cause death by respiratory paralysis. Various organic compounds, have been photocatalytically degraded, but negligible information is available on the fate of acetaldehyde, after photocatalytic degradation over cadmium sulfide, semiconductor. A systematic investigation was carried out to know the details of such degradation in acetaldehyde. The effect of various parameters on the rate of photocatalytic degradation was observed.

\section{EXPERIMENTAL}

$40 \mathrm{~mL}$ of acetaldehyde was dissolved in $160.0 \mathrm{~mL}$ of doubly distilled water to prepare $3.58 \mathrm{M}$ solution, which is then divided into four parts $(50 \mathrm{~mL}$ each) and placed in four beakers. First beaker containing only acetaldehyde solution was kept in dark. The second beaker containing only acetaldehyde solution was exposed to light. The third beaker having acetaldehyde solution and $0.24 \mathrm{~g}$ of CdS was kept in dark. The fourth beaker, containing acetaldehyde solution and $0.24 \mathrm{~g}$ of CdS was exposed to light.

After keeping these beakers for three hours, the amount of unreacted acetaldehyde was measured in each solution. It was observed that there was no or negligible change in the amount of unreacted acetaldehyde in the first three beakers, whereas in the fourth beaker, the amount of unreacted acetaldehyde decreases with the increasing period of exposure. This reaction follows a photocatalytic route as it requires light as well as semiconductor CdS, both.

\section{A Typical Run}

Photocatalytic degradation of acetaldehyde was observed by taking $3.58 \mathrm{M}$ solution and $0.24 \mathrm{~g}$ of CdS was added to it. This solution was exposed to light intensity $=70 \mathrm{mWcm}^{-2}$ from a 200 Watt tungsten lamp. At regular time interval an aliquot of $2.0 \mathrm{~mL}$ was taken out from the reaction mixture, to which $0.5 \mathrm{~mL}$ of Schiff's solution was added to it. The optical density of this solution was measured with the help of spectrophotometer $\left(\lambda_{\max }=350 \mathrm{~nm}\right)$. 
Table .1: A Typical Run. ${ }^{a)}$

[Acetaldehyde] $=3.58 \mathrm{M}$,

Light Intensity $=70.0 \mathrm{mWcm}^{-2}, \mathrm{CdS}=0.24 \mathrm{~g}$

Temperature $=308 \mathrm{~K}$

\begin{tabular}{|c|c|}
\hline Time (min) & 1 + log O.D. \\
\hline 0 & 0.9162 \\
\hline 10 & 0.9134 \\
\hline 20 & 0.9120 \\
\hline 30 & 0.9093 \\
\hline 40 & 0.9069 \\
\hline 50 & 0.9045 \\
\hline 60 & 0.9024 \\
\hline 70 & 0.8993 \\
\hline 80 & 0.8974 \\
\hline 90 & 0.8953 \\
\hline 100 & 0.8929 \\
\hline 110 & 0.8901 \\
\hline 120 & 0.8874 \\
\hline & $\mathbf{K}=8.52 \times 10^{-6} \mathrm{sec}^{-1}$ \\
\hline
\end{tabular}

${ }^{\text {a) Observation of } 1+\log \text { O.D. against time }}$

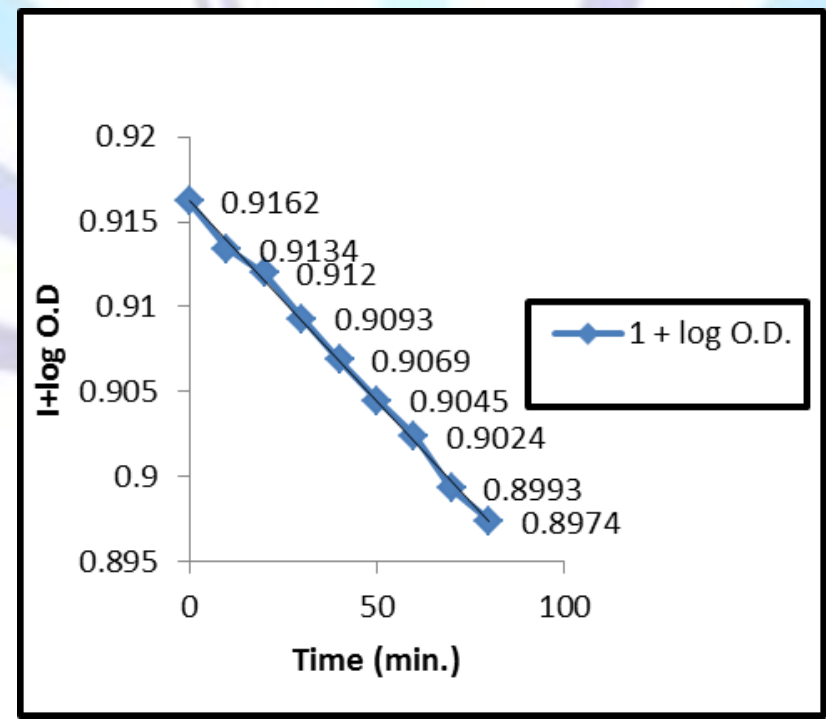

Fig.1: A plot of $1+\log$ O.D. against time 
It was observed that the amount of acetaldehyde decreases with increasing time of exposure. A plot of $1+$ log O.D. against time was linear and the rate constant was measured by the expression $\mathrm{k}=2.303 \times$ slope. The results are reported in the Table.1. and represented by graph in Fig .1.

\section{Mechanism}

On the basis of the observations, a tentative mechanism has been proposed for the photocatalytic degradation of acetaldehyde in the presence of semiconducting CdS powder

hv

$\mathrm{CdS} \longrightarrow \mathrm{e}_{\mathrm{CB}}^{-}+\mathrm{h}^{+} \mathrm{VB}$

$\mathrm{h}^{+} \mathrm{VB} \longrightarrow \mathrm{h}_{\mathrm{s}}^{+}$(s denotes CdS surface).

$\mathrm{H}_{2} \mathrm{O}+\mathrm{h}^{+} \mathrm{s} \longrightarrow \mathrm{OH}+\mathrm{H}^{+}$

$\mathrm{CH}_{3} \mathrm{CHO}+2 \mathrm{OH} \longrightarrow \mathrm{H}_{2} \mathrm{O}+\mathrm{CH}_{3} \mathrm{COOH}$

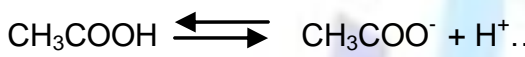

$\mathrm{CH}_{3} \mathrm{COO}^{-}+\mathrm{h}^{+} \mathrm{s} \longrightarrow \mathrm{CH}_{3} \mathrm{COO}$

$\mathrm{CH}_{3} \mathrm{COO} \longrightarrow \dot{\mathrm{C}} \mathrm{H}_{3}+\mathrm{CO}_{2}$

$\mathrm{H}^{+}+\mathrm{e}_{\mathrm{CB}}^{-} \rightarrow \dot{\mathrm{H}}$

$\dot{\mathrm{C}} \mathrm{H}_{3}+\dot{\mathrm{H}} \longrightarrow$

$\mathrm{CH}_{4}$

$\dot{\mathrm{C}} \mathrm{H}_{3}+\dot{\mathrm{C}} \mathrm{H}_{3}$

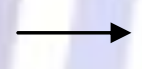

$\mathrm{C}_{2} \mathrm{H}_{6}$.

$\dot{\mathrm{H}}+\dot{\mathrm{H}}$<smiles>[CH]1CCC1</smiles>

$\dot{\mathrm{OH}}+\dot{\mathrm{OH}}$<smiles>O[14CH2]I</smiles>

On exposure of CdS particles, an electron from the valence band is excited to conduction band ( $e_{C B}^{-}$) leaving behind a hole in the valence band $\left(\mathrm{h}^{+}{ }_{\mathrm{vB}}\right)$. This hole creates electron deficiency $\left(\mathrm{h}_{\mathrm{s}}^{+}\right)$at semiconductor surface ${ }^{11}$, which can dissociate water into hydroxyl radical and a proton ${ }^{12}$. This hydroxyl radical abstracts a hydrogen from acetaldehyde with the formation of acetic acid. The acetic acid may dissociate to give acetate ions and a hole can convert it into acetate radicals which may further decarboxylate to generate methyl radicals. There is a possibility of hydrogen radical generation by combination of a proton with an electron in the conduction band and this hydrogen radical can combine with methyl radical to form methane gas; however, the possibility of dimerization of methyl, hydrogen and hydroxyl radicals to give ethane, hydrogen and hydrogen peroxide, respectively, cannot be ruled out.

The formation of carbon dioxide was detected by its usual test with lime water. The presence of acetic acid as an intermediate has been confirmed by taking a drop of the test solution on a spot plate with a drop of $5 \%$ solution of lanthanum nitrate, a drop of $0.01 \mathrm{~N}$ iodine solutions. Then a drop of $1 \mathrm{~N}$ ammonia was added and a blue to brown ring was developed around the drop of ammonia within a few minutes ${ }^{13}$.

The reaction was carried out in the presence of hydroxyl radical scavenger like 2-propanol and it was observed that the rate of photocatalytic degradation of acetaldehyde was drastically reduced; hence, confirming the participation of hydroxyl radical as an active oxidizing species. 


\section{References}

[1] Tanaka K, Kogyoyosui, 1986, 332, 2

[2] Steinbach F, Mem.Soc Raj. Socio. Liege. Collect., 1971, 1, 267

[3] Pelizzetti E, Barbeni M, Pramauro E, Bargarello E, Erbs W, Jamieson M and Serpone N, Quim. Nova, 1985, 8, 288

[4] Suresh C. Ameta, Rameshwar Ameta, Punjabi P B, Sharma B K, Anita Lodha, Asian J. Chem. Revs., 1992, 3,1

[5] Matsuoka S, Kohguki T, Nakamura A, Pac C and Yanagida S, J. Chem. Soc. Chem. Commun., 1991, 58

[6] Ikeda K, Hashimoto K and Fujishima A, J. Electroanalytical Chem., 1997, 437, 241

[7] Khannanov N K, Menchikova G N and Grigoryan E A, Kinet. Catal., 1997, 38, 801

[8] Sano T, Negeshi N, Uchino K, Tanaka J, Matsuzawa S, Takeuchi K, J. Photochem. Photobiol., 2003, 160(A), 93-98

[9] Xiao-xing Fan, Tao YU, Li-zhi Zhang, Xin-yi Chen, Zhi-gang Zou, Chin. J. Chem. Phys., 2007, 20(6), 733-738

[10] Carrera R, Vazquez A L, Castillo S, E.M Arce Estrada., 2011, 691, 92-98

[11] Wu Y, LI Y, Zhuang Q, J. Photochem. Photobiol., 1991, 62A, 261

[12] Sakata T, Kawai T, Hashimota K, J. Phys. Chem., 1984, 88, 2344

[13] Krueger D, Tschirch E, Mikrochemie, 1930, 8, 218 